\title{
The Changing Patterns of Systemic Fluoride Intake
}

\section{B.A. BURT}

\author{
School of Public Health, The University of Michigan, Ann Arbor, Michigan 48109-2029
}

Fluorosis prevalence has increased in North America since the 1930 's-1940's. It may also have increased since 1970 , though the evidence for that is less clear. Continued monitoring will help determine whether increased fluorosis prevalence in children in the United States is a cohort effect from the 1970's. This review considers the evidence for an increase in fluoride ingestion from all sources since the 1970 's. If an increase has occurred, the most likely sources are fluoride dietary supplements, inadvertent swallowing of fluoride toothpastes, and increased fluoride in food and beverages. For adults, there is no evidence from dietary surveys to show that fluoride intake has increased over the last generation. Dietary surveys for children aged six months to two years are similarly inconclusive, though the great variation in fluoride content of various infant foods might be obscuring real effects. The data on fluoride intake by children from food and beverages, infant foods included, are not strong enough to conclude that an increase in fluoride ingestion has occurred since the 1970's. However, the suggested upper limit of fluoride intake is substantially being reached in many children by ingestion of fluoride from food and drink (0.2-0.3 mg per day) and from fluoride toothpaste $(0.2-0.3 \mathrm{mg}$ per day). Two public health issues that arise from this review are: (a) the need for a downward revision in the schedule for fluoride supplementation, and (b) education on the potential for high fluoride concentration of soft drinks and processed fruit juices.

\section{J Dent Res 71 (Spec Iss):1228-1237, May, 1992}

\section{Introduction.}

In a major research contribution during the early days of water fluoridation, McClure (1943) estimated the fluoride intake of children $1-12$ years old to be between $0.4 \mathrm{mg}$ and $1.7 \mathrm{mg}$ per day, depending on age, nature of the diet, and fluoride content of the water. In McClure's time, naturally-fluoridated water was virtually the only exposure to fluoride, but exposure to fluoride in North America nowadays comes from a variety of sources (Ismail et al., 1987; Szpunar and Burt, 1990). The subject of fluoride ingestion, however, has received only sporadic research attention. Fluoride intake among infants received some study during the 1970's in response to concerns about the fluoride content of infant formulae, and further impetus came with a report that the fluoride intake from the food chain could be generally increasing (Leverett, 1982). Research evidence also showed that (a) the prevalence of fluorosis seemed to be increasing among children, and (b) fluoride from dental products intended for topical use could be a substantial source of systemic fluoride.

It is generally acknowledged that fluoride ingestion from all sources in North America has increased since the early studies of the 1930 's-40's. This paper examines the evidence for whether it has increased over the last generation or so. Given the context of this workshop, data sources on fluoride intake will be restricted to those from the United States and Canada. The paper will focus on children in the first eight years of life, because it is during this period that excessive fluoride intake is manifested as dental fluorosis. The concept of "fluoride intake" will be expressed as averages or as ranges, and the nature of the review requires at least a brief discussion of the concept of "optimum fluoride intake" during childhood.

Presented at the Workshop on Changing Patterns of Fluoride Intake, held at the University of North Carolina, Chapel Hill, April 23-25, 1991
Aspects of this subject have been comprehensively reviewed on at least two recent occasions, first at the International Symposium on Fluorides (Georgia, 1989), and then at the Symposium on Appropriate Use of Fluorides (Boston, 1990; published in the J Dent Res and the $J$ Public Health Dent, respectively). As a result, some of the subject matter in this review has been well-covered recently. Where that was the case, I gave the subject a rather cursory review rather than simply repeating what has already been said very well.

An inherent problem with the subject of changing fluoride ingestion is a high degree of variability in (a) the quantity and quality of the human diet and the use of fluoride-containing products, and (b) fluoride content in different foods and drinks, and in different samples of the same food or drink. When added to the methodological problems in determination of the minute amounts of fluoride usually being assessed, either in various products or absorbed by the body, it is apparent that total precision is impossible. Nonetheless, estimates for most measures can be provided with sufficient precision to permit reasonable conclusions to be reached.

\section{Evidence for an increase in fluoride consumption: Dental fluorosis.}

Dental fluorosis is a condition of permanent hypomineralized change, with increased surface and sub-surface enamel porosity resulting from excess fluoride reaching the developing tooth prior to eruption (Fejerskov et al., 1990). The margin of safety between the beneficial effects of fluoride and the first detectable toxic reaction is small, only about 2-5 times (Myers, 1978), so that amounts used and ingested have to be determined fairly precisely. The stable plateau level of plasma fluoride in the healthy adult is around $1.5 \mu \mathrm{mol} / \mathrm{L}(0.028 \mu \mathrm{g} /$ $\mathrm{mL}$, and it has long been believed that it is the frequent "spikes" of increase, rather than increases in the plateau level, which lead to fluorosis (Myers, 1978).

Dental fluorosis is a dose-response condition, so that higher intakes during the critical period of tooth development will result in more severe fluorosis (Dean, 1942; Larsen et al., 1987). However, the relationship between dental fluorosis and fluoride intake in any one individual is not necessarily direct, for there are a number of physiological conditions known to affect enamel development and whether dental fluorosis manifests or not (Angmar-Månsson and Whitford, 1990). These conditions include calcium deficiency, disorders in acidbase balance, disruptions of urinary flow and renal handling of fluoride, and the nature of the diet (Ekstrand et $a l ., 1982$ ). Further evidence of considerable variation among individuals is that the epidemiological evidence is not consistent with the concept of a consistent threshold level for fluorosis (Myers, 1983).

Although it is a severe public health problem in some parts of the world (Chandra et al., 1980; Jolly et al., 1968; Haimanot et al., 1987), there has never been reason to view dental fluorosis as a public health problem in North America. Over the past 30 years, only five cases of crippling skeletal fluorosis have been reported in the United States (US Public Health Service, 1991). The Environmental Protection Agency (EPA) considers unsightly fluorosis a cosmetic rather than a health problem, and has defined $4.0 \mathrm{mg} / \mathrm{L}$ fluoride as the Maximum Contaminant Level permitted for drinking waters in the United States (Environmental Protection Agency, 1986). Only some 166,000 people, or less than $0.1 \%$ of the population of the United States, live in such areas. While severe dental fluorosis is found in the warmer climatic zones of the United States at concentrations below $4.0 \mathrm{mg} / \mathrm{L}$ fluoride (Eklund et al., 1987), the population affected, again, is small. 
Less severe fluorosis, however, is much more common. Even at the optimum levels (around $1.0 \mathrm{mg} / \mathrm{L}$ fluoride for most of the United States), it has been documented for years that from $7-16 \%$ of children born and reared in an optimally-fluoridated area exhibit mild or very mild dental fluorosis in the permanent dentition(Dean, 1942; Russell, 1962; Ast et al., 1956). This level of prevalence was reported at a time when drinking waters were virtually the only source of fluoride.

In the nearly 30 years since the most recent of those reports, however, there is strong evidence that the prevalence of fluorosis has increased. In the National Survey of Dental Caries in US School Children in 1986-87, for example, overall prevalence was reported as 22.3\% (Brunelle, 1989). A noteworthy finding was that fluorosis was found in $18.5 \%$ of 17 -year-olds and $25.8 \%$ of 9-year-olds, a cohort comparison which suggests increasing prevalence, at least during the 1970 's. Several detailed reviews of the literature which compare data over time have concluded that an increase in the prevalence of fluorosis has occurred since the 1930's (Szpunar and Burt, 1987; Pendrys and Stamm, 1990), though the evidence on whether this has been accompanied by an increase in severity is not yet clear. The prevalence increase has not been uniform in all types of communities. While fluorosis is still more prevalent in fluoridated than in nonfluoridated communities, its prevalence has increased proportionately more in non-fluoridated communities (Leverett, 1986; Kumar $2 t$ al., 1989; Pendrys and Stamm, 1990; Williams and Zwemer, 1990). Pendrys and Stamm quantified the change by stating that, in Dean's time, residence in an optimally fluoridated area carried about an 18fold increase in the risk of fluorosis, whereas today that increased risk has dropped to about two-fold (Pendrys and Stamm, 1990). In a recent study in Québec, fluorosis among 11-17-year-old students in fluoridated Trois-Rivieres was approximately double that in nonfluoridated Sherbrooke (Ismailet al., 1990).

A series of semi-longitudinal assessments of fluorosis in seven naturally-fluoridated communities in northern Illinois highlighted the nature of the change over recent years (Driscoll et al., 1986; Heifetz et al., 1988). The researchers from the National Institutes of Health initially concluded that the prevalence of fluorosis in 8-16- year-olds had not increased significantly since Dean's surveys in the 1930's (Driscoll et al., 1986). In a later report, however, significant increases in prevalence were detected in 13-15-year-old cohorts between 1980 and 1985 (Heifetz et al., 1988). However, significant increases could not be discerned among 8-10-year-old cohorts over the same period, and longitudinal comparisons showed no change in prevalence or severity. Relating age to fluorosis and tooth calcification, the authors concluded that fluoride intake had increased during the 1970-77 period and had not increased much subsequently. An increase in fluorosis during the same period of the 1970 's is also implied by the results of Leverett (1986).

The evidence supports the conclusion that the prevalence of fluorosis has increased over the last $30-50$ years, and that the relative increase has been sharpest in non-fluoridated communities. Dental fluorosis, however, is not a public health problem in North America, for almost all dental fluorosis in the United States and Canada at this time is, at most, a debatable esthetic issue.

\section{Fluoride as an essential nutrient; optimum fluoride intake.}

The National Research Council (1974) once listed fluoride as an essential nutrient, but subsequently took the more cautious position that fluoride is a "...beneficial element for humans" because of its positive impact on dental health (National Research Council, 1989). The Council amended its stance because an essential role for fluoride in human growth studies had not been confirmed, and because a physiological mechanism by which fluoride would influence growth had not been demonstrated. Available evidence does not justify classifying fluoride as an essential element by accepted standards (National Research Council, 1989).

Guidelines on the "optimum" intake of fluoride in children have an interesting history. In the same 1943 report in which he estimated that the "average daily diet" contained $1.0-1.5 \mathrm{mg}$ of fluoride, McClure (1943) suggested that this same diet provided some $0.05 \mathrm{mg}$ fluoride/kg body weight/day for children aged 1-12 years. This information later came to be interpreted as a recommen-

TABLE 1

ESTIMATED INTAKE OF FLUORIDE FROM FOOD AND DRINK BY NORTH AMERICAN ADULTS, 1943 TO 1987, EXPRESSED AS RANGES OR MEAN VALUES (all quantities in mg per day)

\begin{tabular}{lcc}
\hline \hline Report & $\begin{array}{c}\text { Fluoridated } \\
(0.7 \text { ppm F or more })\end{array}$ & $\begin{array}{c}\text { Non-fluoridated } \\
(0.3 \text { ppm F or less })\end{array}$ \\
\hline McClure (1943) & $1.4-1.8$ & $0.3-0.5^{*}$ \\
McClure and Zipkin (1958) & $1.3-1.5$ & \\
Cholak (1959) & $2.1-2.4$ & \\
Filippo and Battistone (1971) & $1.7-3.4$ & $0.8-1.0$ \\
Kramer et al. (1974) & $1.6-1.7$ & 0.9 \\
Osis et al. (1974) & 1.7 & 0.9 \\
Singer et al. (1980) & $1.2-1.5$ & \\
Spencer et al. (1981) & 1.8 & 0.9 \\
Taves (1983) & 1.9 & 0.6 \\
Singer et al. (1985) & 2.8 & \\
Dabeka et al. (1987) & & \\
\hline
\end{tabular}


dation, as when Farkas and Farkas (1974) quoted a number of personal opinions which recommended that fluoride intake be measured as a function of body weight. They did not refer to McClure, and not all of their sources who suggested $0.06 \mathrm{mg}$ fluoride/kg body weight/day would be universally accepted as fluoride experts. A few years later, Ophaug et al. (1980b) stated that 0.05-0.07 mg fluoride/kg body weight/day "...is generally regarded as optimum". Ophaug et al. (1980b) cited as their sources Farkas and Farkas (1974), already discussed, and Forrester and Schulz (1974), where the reference could not be found. Despite its dubious genesis, however, empirical evidence suggests that $0.05-0.07 \mathrm{mg}$ fluoride/kg body weight/day remains a useful upper limit for fluoride intake in children.

Fluorosis is considered probable following intakes of $0.1 \mathrm{mg}$ fluoride/kg body weight during infancy (Forsman, 1977). More recent reports, however, have suggested a lower threshold: 0.03 $0.10 \mathrm{mg}$ fluoride/ $\mathrm{kg}$ body weight has been suggested as the borderline zone (Fejerskov et al., 1987), at least for European children. Studies in Kenya have reported fluorosis developing with average daily intakes as low as $0.04 \mathrm{mg}$ fluoride $\mathrm{kg}$ body weight (Baelum $\mathrm{et}$ al., 1987). Although some nutritional factors could be influencing these estimates (Angmar-Månsson and Whitford, 1990), their lower limits still fall below the "optimum" of $0.05-0.07 \mathrm{mg}$ fluoride $/ \mathrm{kg}$ body weight/day.

\section{The critical period for fluorosis development.}

For years it was assumed that fluoride absorbed during the secretory phase of tooth development had the greatest effect on fluorosis, but more recent research with animals (Johnson and Bawden, 1987; Richards et al., 1986) and humans now suggests that the later maturation phase is more important. Where fluorosis is found among human populations, observers have noted that teeth which mineralize later in life generally show more severe fluorotic disturbances than do those that mineralize earlier(Baelumet al., 1987; Larsen et al., 1985, 1987, 1989). This finding is attributed to the older children's ingesting greater absolute amounts of fluoride in single dosages than do younger children, thus exacerbating the "spiking" effect of plasma fluoride. The initial research reports that used the Fluorosis Risk Index (Pendrys and Katz, 1989) have permitted epidemiological identification of the maturation period as the critical stage of tooth development as far as fluorosis is concerned (Pendrys and Katz, 1989; Pendrys and Stamm, 1990). On a larger scale, the 1978 reduction in the fluoride concentration of Hong Kong's drinking water from $1.0 \mathrm{mg} / \mathrm{L}$ to $0.7 \mathrm{mg} / \mathrm{L}$ allowed various birth cohorts to be studied so that the effect of this change could be evaluated. Not only did fluorosis diminish, but also the importance of the maturation stage in fluorosis development was

TABLE 2

ESTIMATED FLUORIDE INTAKE FROM FOOD AND DRINK BY NORTH AMERICAN CHILDREN, 1943 TO 1985 , EXPRESSED AS RANGES OR MEAN VALUES

\begin{tabular}{|c|c|c|c|c|c|}
\hline \multirow[b]{2}{*}{ Report } & \multirow[b]{2}{*}{ Age } & \multicolumn{2}{|c|}{ mg F/kg Body Weight/Day } & \multicolumn{2}{|c|}{ mg F/Day } \\
\hline & & Fluoridated & Non-fluoridated & Fluoridated & Non-fluoridated \\
\hline \multirow[t]{3}{*}{ McClure (1943) } & $1-3 \mathrm{yrs}$. & $0.03-0.10$ & & $0.42-0.83$ & \\
\hline & $4-6$ yrs. & $0.02-0.09$ & & $0.56-1.11$ & \\
\hline & $7-9 \mathrm{yrs}$ & $0.02-0.07$ & & $0.70-1.38$ & \\
\hline \multirow[t]{2}{*}{ Wiatrowski et al. (1975) } & $1-4$ weeks & & 0.07 & & 0.32 \\
\hline & 4-6 mos. & & 0.16 & & 1.23 \\
\hline \multirow[t]{3}{*}{ Singer and Ophaug $(1979)^{1}$} & 2 mos. & 0.13 & 0.01 & 0.63 & 0.05 \\
\hline & 4 mos. & 0.10 & 0.02 & 0.68 & 0.10 \\
\hline & $6 \mathrm{mos}$. & 0.09 & 0.02 & 0.76 & 0.15 \\
\hline Ophaug et al. $(1980 \mathrm{a})^{2}$ & $6 \mathrm{mos}$. & 0.03 & 0.04 & 0.21 & 0.35 \\
\hline Ophaug et al. $(1980 \mathrm{~b})^{2}$ & 2 yrs. & 0.05 & 0.03 & 0.61 & 0.32 \\
\hline \multirow[t]{2}{*}{ Dabeka et al. (1982) } & 3-6 mos. & 0.06 & 0.04 & 0.42 & 0.25 \\
\hline & $9-12$ mos. & 0.05 & 0.03 & 0.56 & 0.28 \\
\hline \multirow[t]{2}{*}{ Ophaug et al. $(1985)^{3}$} & 6 mos. & 0.05 & 0.03 & 0.42 & 0.23 \\
\hline & 2 yrs. & 0.05 & 0.02 & 0.62 & 0.21 \\
\hline Featherstone and Shields (1988) & 6 mos. & 0.05 & 0.03 & 0.4 & 0.2 \\
\hline
\end{tabular}

${ }_{1}^{1}$ "Fluoridated" calculated as a maximum; foods processed with $\mathrm{F}$ water and mixed with $\mathrm{F}$ water. "Non-fluoridated" calculated as a minimum; foods processed with non-F water and mixed with non-F water.

2 "Market basket" survey. Fluoridated community was Grand Rapids, MI (1.04 mg/L F), non-fluoridated is Los Angeles, CA (0.37 mg/ L F).

3 "Market basket" survey. Fluoridated is mean of communities $\geq 0.7 \mathrm{mg} / \mathrm{L} \mathrm{F}$; non-fluoridated is mean of communities $\leq 0.3 \mathrm{mg} / \mathrm{L}$ F.

4 "Market basket survey. Fluoridated community was Rochester, NY (1.0 mg/L F), non-fluoridated was Ithaca, NY (<0.2 mg/L F). 
clearly demonstrated (Evans, 1989). Evans concluded that the development of dental fluorosis may occur over a period of 1624 months, commencing from 12-32 months following enamel secretion (Evans, 1989).

The evidence thus suggests that the maturation phase of tooth development is more critical for fluorosis than is the earlier, secretory, phase, though the relationship between quantity and timing of fluoride intake in both phases needs further definition. The implications of these conclusions are that, whereas risk factors for fluorosis need to be generally curtailed, they may need particular control during enamel maturation. If, as the EPA states, the type of fluorosis generally seen in North America is an esthetic rather than a health concern, then we are principally concerned about the anterior teeth. The research evidence suggests that the critical time for fluorosis development in anterior teeth may be the second or third year of life (Johnson and Bawden, 1987). This important issue will be brought up later after the potential sources of increase in fluoride intake are reviewed.

\section{Air-borne fluorides.}

Air intake of fluoride is usually negligible, around $0.04 \mathrm{mg}$ fluoride/day in most North American environments (Whitford, 1986). Exceptions can occur around some industrial plants which work with fluoride-rich material, such as aluminum smelters without safeguards to prevent the escape of fluoride-containing compounds (Haikel et al., 1986). Such local environmental hazards should be controlled to the extent possible, and nowadays they are uncommon in North America. There is no evidence that intake of fluoride from air-borne sources in North America has increased over recent years.

\section{Fluoridated water.}

Dean stated that some $10 \%$ of children in optimally-fluoridated areas were affected by fluorosis (Dean, 1942), an average figure which covered a wide range in different communities. Pendrys and Stamm (1990) concluded in their review that the prevalence of fluorosis in fluoridated areas has remained relatively stable since the 1930 's. Despite the growth of other sources of fluoride intake since then, fluorosis prevalence in different communities is still correlated with the fluoride content of drinking water (Szpunar and Burt, 1988). The growth of fluoridated communities since Dean's time means that a greater proportion of the national population would now be affected, though not necessarily a greater proportion in any one fluoridated community. Fluoridated water probably has its greatest impact on fluorosis prevalence indirectly, through being used in the processing of infant formulae, other children's foods, and soft drinks.

\section{Fluoride gels and rinses.}

Fluoride gel treatments have been associated with the swallowing of relatively high amounts of fluoride (Whitford et al., 1987); up to $0.5 \mathrm{mg}$ fluoride per treatment have been recorded (Larsen et al., 1985). Plasma fluoride levels can rise sharply and be accompanied by acute symptoms of dizziness and nausea when high-concentration gel is swallowed (Ekstrand and Koch, 1980). Whitford and colleagues suggest that the amounts swallowed are sufficient to cause dental fluorosis (Whitford et al., 1987), though for such fluorosis to be esthetically critical the gel would need to be swallowed by a young child. The recent review by Ripa (1991) repeated the precautions to be taken during gel treatments for minimization of inadvertent swallowing. Since these precautions have been taught in dental schools and propagated among dental professionals for some years now, the ingestion of fluoride from gels by young children should at least not be increasing, and may actually be decreasing. Although the potential problem is recognized, there is no evidence that swallowing of fluoride gels has been a factor in the increase in fluorosis among North American children.

Ripa's review (Ripa, 1991) concluded that consistent swallowing of the $230 \mathrm{mg} / \mathrm{L}$-fluoride-concentration mouthrinse used in the daily rinsing regimen could potentially increase the risk of fluorosis in young children. However, fluoride rinses are not recommended in children younger than 5 years of age. Ripa (1991) also recommended that kindergarten children not be included in school-based rinsing programs, or at least that they rinse with reduced amounts of solution. There is no evidence that the swallowing of fluoride mouthrinses has increased in recent years, though the potential misuse of mouthrinses is an issue that should continue to be monitored.

TABLE 3

FLUORIDE CONTENT OF MILK-BASED INFANT FORMULAE IN NORTH AMERICA, 1974-1987, REPORTED AS MEANS OR RANGES (expressed as mg/L fluoride)

\begin{tabular}{|c|c|c|c|}
\hline Report & Ready-to-Use & Liquid Concentrate & Powdered \\
\hline Farkas and Farkas $(1974)^{1}$ & $0.90-1.00$ & $0.60-0.70$ & 0.50 \\
\hline Wiatrowski et al. (1975) & $0.25-0.32$ & $0.72-0.97$ & \\
\hline Tinanoff and Mueller (1978) & $0.20-0.86$ & $<0.10-0.40$ & \\
\hline \multirow[t]{2}{*}{ Singer and Ophaug (1979) } & $0.10-0.36^{2}$ & $0.12-0.17^{2}$ & \\
\hline & $0.22-0.98^{3}$ & $0.22-0.85^{3}$ & \\
\hline Johnson and Bawden (1987) & 0.21 & 0.10 & 0.10 \\
\hline Dabeka et al. (1987b) & 0.84 & 0.60 & 1.13 \\
\hline McKnight-Hanes et al. (1988) & $0.09-0.16$ & $0.10-0.14$ & 0.06 \\
\hline
\end{tabular}

\footnotetext{
${ }^{1}$ Quoting 1963 data.

${ }^{2}$ Processed at non-fluoridated plants.

${ }^{3}$ Processed at fluoridated plants.
} 


\section{Fluoride toothpastes.}

Children aged 3-5 years have been found to swallow up to 0.25$0.5 \mathrm{~g}$ of toothpaste, amounts which contain $0.25-0.5 \mathrm{mg}$ fluoride (Hargreaves et al., 1970, 1972; Naylor et al., 1971; Barnhart et al., 1974; Baxter, 1980). Fluoride from toothpaste is readily bioavailable (Ellingsen and Ekstrand, 1985), and plasma fluoride levels rise sharply when children swallow fluoride-containing toothpaste (Ekstrand and Ehrnebo, 1980; Trautner and Einwag, 1988). Research studies with 3-4-year-old children, each of whom swallowed $0.6 \mathrm{~g}$ of toothpaste, found that the rise in plasma fluoride was equivalent to that seen after ingestion of a 0.5 -mg-fluoride dietary supplement (Ekstrand et al., 1983). Studies with pre-schoolers in the Québec area have found that from 30 to $50 \%$ of toothpaste used is swallowed, with 3-yearolds swallowing around 50\% (Simard et al., 1989; Naccache $e t$ $a l ., 1990)$. The quantities of fluoride swallowed by 2-3-yearolds in the Québec studies averaged $0.3 \mathrm{mg}$ per day. The conditions in the Québec studies were artificial, so the proportions of toothpaste swallowed in those studies might be higher than would occur in normal home conditions.

Older children swallow less toothpaste during brushing than do the younger ones; a study of children 8-10 years old found average retention from each brushing to be around $0.12 \mathrm{mg}$ fluoride (Glass et al., 1975). One study found no relation between the use of a high-strength fluoride toothpaste $(2400$ ppm F) in infancy and later development of fluorosis, though the data-collection methods used in this study might have been too loose to permit a firm conclusion to be drawn (Houwink and Wagg, 1979).

A well-conducted case-control study in the fluoridated Toronto area found that use of fluoride toothpaste before the age of 2 years increased the odds of later development of fluorosis 11 times (Osuji et al., 1988), though the fluorosis concerned was very mild. Comparable findings came from a British study, where diffuse enamel defects were more prevalent among children of higher socio-economic status whose parents had commenced brushing their teeth at an early age than they were among those for whom toothbrushing began later (Milson and Mitropoulos, 1990). Early use of fluoride toothpaste and dietary supplements was also reported to be related to fluorosis in a Dutch study (Woltgens et al., 1989), though the relative impact of each regimen was not separated out. On the other hand, a Swedish study could not detect additional risk of fluorosis among children who began using fluoride toothpaste between the ages of 6 and 12 months (Holm and Andersson, 1982).

The inadvertent swallowing of fluoride toothpastes has to be seen as a measurable part of daily fluoride intake. Available data support the conclusion of Ripa (1991), who estimated from existing studies that the average daily amount of fluoride ingested by a pre-school child, brushing twice daily with a standard-strength toothpaste $(1000-1100 \mathrm{ppm} \mathrm{F})$ was $0.27 \mathrm{mg}$. When used by young children, fluoride toothpaste is thus a potential risk factor for dental fluorosis, although the research evidence to confirm this relationship is not strong.

Because of their potential to contribute to fluorosis, the use of higher-concentration fluoride toothpastes is strongly discouraged in young children, and the continued testing of appropriate lower-concentration fluoride toothpastes for children is encouraged (Beltran and Szpunar, 1988). Tests of toothpastes containing $500-550 \mathrm{ppm} \mathrm{F}$ have given good results (Triol et al, 1987; Winter et al., 1989), and manufacturers are encouraged to look for ways to market them for children. Other means of reducing the amounts of fluoride used, and therefore retained, are also encouraged, such as pumps or use of a smaller orifice in a standard tube (Bruun and Thylstrup, 1988).

\section{Fluoride dietary supplements.}

It is beyond the scope of this review to include either the efficacy of dietary fluoride supplements in caries prevention, or the preeruptive vs. post-eruptive benefits of fluoride, though both issues have to be considered when the whole issue of fluoride supplements is being reviewed. Evidence is building, however, to show that there is a strong risk of mild-to-moderate fluorosis associated with the use of fluoride supplements. It is likely that

TABLE 4

ESTIMATED DAILY FLUORIDE ALLOWANCES FOR CHILDREN AGED 3 MONTHS-8 YEARS (See text for explanation.)

\begin{tabular}{lcccc}
\hline \hline Age & Weight & $\begin{array}{c}\text { Energy } \\
\text { Allowance } \\
\text { (Kcals) }\end{array}$ & $\begin{array}{c}\text { Upper F } \\
\text { Limit (mg) }\end{array}$ & Range $^{2}$ \\
\hline 3 mos & $5-7$ & 650 & 0.33 & $0.05-0.07$ \\
6 mos & $6-9$ & 650 & 0.33 & $0.04-0.06$ \\
12 mos & $8-12$ & 850 & 0.43 & $0.04-0.05$ \\
18 mos & $9-13$ & 1300 & 0.65 & $0.05-0.07$ \\
24 mos & $10-15$ & 1300 & 0.65 & $0.04-0.07$ \\
30 mos & $11-16$ & 1300 & 0.65 & $0.04-0.06$ \\
36 mos & $12-17$ & 1300 & 0.65 & $0.04-0.05$ \\
4 years & $14-20$ & 1800 & 0.90 & $0.05-0.06$ \\
6 years & $17-27$ & 1800 & 0.90 & $0.03-0.05$ \\
8 years & $22-34$ & 2000 & 1.00 & $0.03-0.05$ \\
\hline
\end{tabular}

${ }^{1}$ Kilograms, 10 th and 90 th percentiles, rounded for boys and girls combined.

${ }^{2} \mathrm{mg} \mathrm{F} / \mathrm{kg}$ body weight/for 10 th and 90 th weight percentiles. 
past use of dietary fluoride supplements has been a prime factor in the increased prevalence of dental fluorosis, a relationship which may stem from the days when fluoride supplement schedules were higher than they are today.

The American Dental Association (ADA) and the American Academy of Pediatrics (AAP) maintained separate schedules of recommended dosage for fluoride supplements prior to 1979 . The AAP had first recommended $0.5 \mathrm{mg}$ per day (American Academy of Pediatrics, 1972) for children under 2 years of age, whereas the ADA recommended $0.25 \mathrm{mg}$ per day. The AAP altered its earlier recommendations in 1979 (American Academy of Pediatrics, 1979) to bring them into line with those of the $\mathrm{ADA}$ (American Dental Association, 1984) and re-affirmed them in 1986 (American Academy of Pediatrics, 1986). In the meantime, however, many children were prescribed what are now considered excessive amounts of fluoride as dietary supplements. One frequently-quoted study in the Boston area that used the old AAP schedule, for example, was successful in terms of caries reduction, but $67 \%$ of the children developed very mild/ mild fluorosis (Aasenden and Peebles, 1974). There is other evidence that excessive fluoride ingestion in infancy and early childhood through inappropriate prescription of fluoride supplements has been widespread in the past (Margolis et al., 1980).

Several recent studies point to the role of dietary fluoride supplements in the increasing prevalence of fluorosis. A recent case-control study found that exposure to fluoride supplements, together with higher socio-economic status, increased the risk of fluorosis development by a factor of 28 (Pendrys and Katz, 1989). When added to other studies on this subject (Ismail et al., 1990; Pendrys and Stamm, 1990), there is good evidence for viewing fluoride supplements as a primary risk factor in dental fluorosis. Perhaps that message is being heard by practitioners, for in a telephone survey during the preparation of this review, major manufacturers of fluoride dietary supplements reported that sales of fluoride supplements have remained generally stable since 1979 , and perhaps have even decreased. The use of fluoride supplements in modern conditions-especially now that measurable intake of fluoride from food, beverages, and toothpaste is well-recognizedneeds careful review.

\section{Consumption of fluoride in food and drink: adults.}

Fluoride's abundance in soils and plants means that everyone consumes fluoride, whether he wants to or not. Absorption of fluoride from the diet, however, can vary from one individual to another and in the same individual from one occasion to another. Apart from the systemic disorders mentioned earlier, absorption of fluoride is hindered if calcium, magnesium, or aluminum ions are present, because these cations can "bind" $F$ (Whitford, 1986).

Data on the quantities of fluoride in the adult diet extend back to McClure's pioneering work in the 1940 's. Older, frequentlyquoted estimates of daily fluoride in take from food and beverages for an adult male have included $1.0-3.0 \mathrm{mg}$ in a non-fluoridated area and 2.0-5.0 mg in a fluoridated area (Marier and Rose, 1972). Most studies on adult intake of fluorides have been published since 1971. The results of these and earlier studies are arranged in descending chronological order in Table 1, separated into estimates for fluoridated and for non-fluoridated areas.

Given the variety of methods used, both in the collection of food consumption data and in laboratory assays of fluoride content, the data appear to be remarkably uniform. This is especially so for the non-fluoridated areas. The larger degree of variation for the fluoridated areas comes principally with different estimates of water and other beverages consumed, for in fluoridated areas water consumption contributes some three-quarters of total fluoride intake (Singer et al., 1985). Several of these studies are of hospital inpatients consuming a hospital diet (Kramer et al., 1974; Osis et al.,
1974; Spencer et al., 1981), others are part of a series of "market basket" surveys of dietary habits of adults in American communities, and one is from Canada (Dabeka et al., 1987a). A mild caveat about the data in Table 1 is that some of the earlier data-that is, prior to the 1960 's-may have been overestimates, because the colorimetric methods then in use could react with ions other than fluoride (Rao, 1984). Most of the data in Table 1, however, would not have been affected. Collectively, the data in Table 1 give little reason to believe that fluoride consumption has been increasing among North American adults over the last generation. Even when compared with intakes in Dean's time, Taves (1979) estimated that any increase in fluoride consumption from foods and drink would not have exceeded $10 \%$. Collectively, the data give no reason to believe that there is any cause for public health concern with adult consumption of fluoride.

\section{Consumption of fluoride in food and drink: children.}

It was reported 20 years ago that human milk contains very low concentrations of fluoride, estimated to be no more than $0.02 \mathrm{mg} / \mathrm{L}$ (Ericsson and Ribelius, 1971). More recent studies find an even lower concentration, around 0.005-0.01 mg/L (Ekstrand et al., 1984a; Dabeka et al., 1986). Breast-fed infants receive some $0.006 \mathrm{mg}$ of fluoride per day, a quantity low enough to put the infants into negative fluoride balance (Ekstrand et al., 1984a). For a 5-kg infant, this intake is around $0.001 \mathrm{mg}$ fluoride $/ \mathrm{kg}$ body weight/day. The fluoride concentration of breast milk, it will be noted, is lower than its stable level in plasma, which Myers (1978) put at $0.028 \mathrm{mg} / \mathrm{L}$. Plasma fluoride levels also rise and fall with fluoride absorption and excretion (Ekstrand, 1989), but these plasma variations are not transferred to breast milk (Ekstrand et al., 1984b). Even if nursing mothers are exposed to more fluoride today than in previous years, it is evident that the increase is not being passed on to breast-fed infants.

Table 2 shows the average intake of fluoride from food and drink among North American children. McClure's estimates came in the days when naturally fluoridated water was virtually the only significant source of fluoride exposure (McClure, 1943). More recent estimates use "market basket" techniques, while others focus on analysis of fluoride content of infant foods and then use various assumptions to compute estimated intakes. It will be noted that, apart from McClure's estimates, the oldest age studied is 2 years. This probably reflects the research interest in the fluoride content of infant foods through the 1970's and 1980's, and perhaps the implicit assumption that fluoride intake during the earliest months of life was the most critical period for fluorosis.

As was seen with Table 1 , the data in Table 2 appear to be remarkably consistent when all the sources of variation are considered. The one set that stands out from the rest is that of Wiatrowski et al. (1975), and these data have been criticized by Singer and Ophaug (1979). Their criticism is that the caloric intakes used by the Wiatrowski group to estimate the daily fluoride ingestion are too high, thus resulting in overestimates. If that criticism is valid, then the rest of the data in Table 2 are remarkably uniform, and present no obvious evidence of an increase in fluoride intake over time.

Much of the concern about a potential increase in fluorosis has been directed at the fluoride content of infant foods, a subject which has received considerable research attention. The most fundamental infant food, mothers' milk, has been discussed and is clearly not involved. Infant formulae and infant solid foods and juices, however, are a different story; Table 3 shows the means and ranges of fluoride content of milk-based infant formulae in the United States and Canada. Some explanation of the data in Table 3 is required. The data from Farkas and Farkas (1974) are reported from other Canadian sources, some going back to 1963 . They do not provide details of fluoride content of the water used at the processing plant, nor do Wiatrowski et al. (1975). The data from Singer and Ophaug (1979), prepared to respond to the concerns they had with the data 
from Wiatrowski et al., differentiated between products prepared with fluoridated water and those prepared with non-fluoridated water. The two most recent American analyses are of special interest, because they follow the conscious efforts of manufacturers to reduce the fluoride content of infant formulae in the United States. Johnson and Bawden (1987) stated that the values they recorded for the milk-based products were about half of the values recorded in 1980, and McKnight-Hanes and colleagues (1988) reached a similar conclusion. By contrast, Dabeka et al. (1987b), analyzing Canadian products, came up with values that were little different from those in the 1970's. This group also tested some recent American products, and noted that the Canadian formulae generally had up to four times the fluoride content of their American counterparts. In addition to the data shown in Table 3 , researchers are unanimous that soy-based formulae contain more fluoride than the milk-based products (Johnson and Bawden, 1987; McKnightHanes et al., 1988).

The recognition of the problem with the high fluoride content of infant formulae, and the corrective action that manufacturers in the United States have made, is commendable public health action. Canadian manufacturers might be urged to follow suit if they have not already done so. However, the amounts of fluoride ingested by formula-fed infants can still look rather high, especially if the concentrates are diluted with fluoridated water. On the other hand, the bioavailability of fluoride from milk-based formulae has been measured at 65-72\% (Spak et al., 1982), so it is possible that we have overestimated fluoride absorption from infant formulae.

Other foods regularly fed to infants have also been found to contain high quantities of fluoride. Cereals tested in the 1970's have been listed as containing from 4 to 12 ppm fluoride (Farkas and Farkas, 1974), from 0.93 to $2.11 \mathrm{ppm}$ when prepared at a nonfluoridated plant, and from 3.85 to $6.85 \mathrm{ppm}$ when prepared at a fluoridated plant (Singer and Ophaug, 1979). Chicken was also consistently high in fluoride: $1.51-3.14 \mathrm{ppm}$ in one report (Wiatrowski et al., 1975), $5.29 \mathrm{ppm}$ in another (Singer and Ophaug, 1979). Processing of infant chicken in the 1970's was said to incorporate a lot of ground bone, which was probably the source of the high fluoride content. Staff from the National Institute of Dental Research received assurances from manufacturers at the time that the problem was recognized and would be rectified, but the literature does not contain evidence that infant foods such as chicken have since been independently tested.

As children move out of infancy toward their first and second birthdays, fluoride intake relative to body weight is usually considered to decrease (McClure, 1943; Adair and Wei, 1978). There has been little study, however, of fluoride intake through the period 28 years of age, and, as mentioned earlier, the early part of that agerange may be crucial for the development of fluorosis on the anterior teeth. In the absence of data on fluoride ingestion from food and drink in this group, one area of concern is the consumption of soft drinks processed in fluoridated areas. In a non-fluoridated city, Clovis and Hargreaves (1988) found that soft drinks and commercially-prepared fruit juices made in a fluoridated city contained 0.8 $\mathrm{mg} / \mathrm{L}$. The usual 12-ounce can of such drinks would therefore contain $0.28 \mathrm{mg}$ of fluoride. Recent personal communications from the beverage industry confirm that the American appetite for soft drinks seems infinite, with estimates for 1989 per capita consumption at 47.5 gallons. That is the equivalent of 48712 -ounce cans per year, or 1.34 cans per person per day. Soft drinks could easily be a major source of fluoride for some of the heavy soft-drinkers in the younger age groups; three cans per day of such beverages would provide up to $0.84 \mathrm{mg}$ of fluoride.

In our longitudinal study of dietary intake among 10-15-year-old children in the non-fluoridated Coldwater area of Michigan (Burtet al., 1988), the fluoride content of the 100 most commonly consumed foods and drinks was analyzed by Dr. Gary Whitford at the Medical College of Georgia. The fluoride concentrations in the majority of foods were little different from those published by McClure (1949), but one of the major soft drinks, processed in a nearby fluoridated area, contained $0.86 \mathrm{ppm}$ fluoride. Although the data have not been fully analyzed, the average daily fluoride intake from food and drink among a random 40 or so of these teenagers was low, around $0.3 \mathrm{mg}$ fluoride per day. There was, however, considerable variation, with some ingesting more than $1.0 \mathrm{mg}$ per day and several ingesting more than $3.0 \mathrm{mg}$ per day. The impression was that these higher intakes were principally due to high soft-drink consumption. The children concerned in this case, however, were too old for this fluoride intake to be a factor in fluorosis development in anterior teeth.

The research focus on the fluoride content of infant foods has raised the question of how much fluoride an infant should have, an issue recently addressed by questioning whether they need any at all (Leverett, 1991), or at least any more than the minuscule amounts present in mothers' milk. That issue is beyond the scope of this review. However, if we take the position that infants need some systemic fluoride for normal growth and development, some guidelines on how much they should have can be presented from the conclusion of Ekstrand (1989) that the upper limit of fluoride intake for young children should be around $0.05 \mathrm{mg}$ per $100 \mathrm{kcalories}(418.4$ $\mathrm{kJ}$ ) of energy intake. (That figure is a compromise from the conclusions reached by the editors of the Journal of Nutrition, jointly with Ekstrand, that daily fluoride intake should not exceed $0.06 \mathrm{mg} / 100 \mathrm{kcals}$ from powdered concentrate, $0.03 \mathrm{mg} / 100 \mathrm{kcals}$ from liquid concentrates, and $0.07 \mathrm{mg} / 100 \mathrm{kcals}$ from ready-to-feed formulae.) By matching that estimate, taken from Ekstrand's extensive research with fluoride absorption and excretion, with energy allowances for particular ages of infants, we can present the data shown in Table 4.

The first column in Table 4 is the 10th and 90 th percentiles of children's weights at particular ages, taken from Nelson Essentials of Pediatrics (Behrman and Kliegman, 1990). The second column is energy allowances at each age, taken from Recommended Dietary Allowances (National Research Council, 1989). The column of fluoride intake is a broad estimate of the upper limit of fluoride intake per day for children up to 8 years old, as long as the assumptions upon which they are based can be accepted. The range of fluoride intake, in the right-hand column, uses the 10th and 90 th percentiles of children's weights to assess the upper and lower limits of fluoride intake per $\mathrm{kg}$ of body weight for children in each of the ages considered. It will be noted that these estimates match well with the range of "optimum" fluoride intake, which provides some degree of validation to the estimates for maximum fluoride ingestion.

\section{Discussion.}

Study of the amounts of fluoride in infant foods has sharpened the issue of the critical period for the development of fluorosis. If the maturation stage really is the crucial time for fluorosis development, then the research effort into fluoride intake in early infancy may not have been well-directed. Since this is also usually past the infant formula stage, the fluoride content of infant formula may be less of a risk factor than was thought. A case-control study which found infant formula to be a risk factor for fluorosis noted that this finding came with prolonged use of the formula, here meaning 13 months or more (Osuji et al., 1988). Data on fluoride intake from all sources during the second and third year of life are scarce, and require research attention.

There is little doubt that fluorosis prevalence has increased in North America since Dean's time. It may still be increasing, though the data to either support or reject that view are not compelling. As to reasons for the increase, it is possible that the increase in fluorosis now being detected is a cohort effect, a possibility hinted at by Heifetz et al. (1988) in their Illinois studies. A cohort effect would be the result of high fluoride content of infant foods during the 
1970 's, fluoride dietary supplement schedules during the 1970's that were too high, and perhaps over-enthusiastic use of fluoride toothpaste in young children. The data on fluoride intake from food and beverages, infant foods included, may indicate that total fluoride intake in young children is still higher than desirable, but they do not support the view that fluoride intake from food and drink has increased since the 1970's.

One of these likely problems from the 1970's, that of infant foods, seems to have been fairly well-handled in the United States. Better education on the use of fluoride toothpastes in young children might be having some beneficial effects at present, and the marketing of effective lower-strength fluoride toothpastes would reduce that much further the chance of young children ingesting excess fluoride. Assuming that some fluoride intake is desirable, the suggested upper limit of fluoride ingestion is substantially being reached by ingestion of fluoride from food and drink $(0.2-0.3 \mathrm{mg}$ per day) and from fluoride toothpaste (0.2-0.3 $\mathrm{mg}$ per day). That leaves as public health issues to be dealt with (a) the schedule for fluoride supplementation, and (b) further education on the potential for high fluoride concentration of soft drinks and processed fruit juices.

Two research issues requiring attention that emerge from this review are (a) confirmation that the maturation period of tooth development is the most critical time in terms of fluorosis, and (b) data on fluoride intake of children between 2 and 8 years old.

\section{REFERENCES}

Aasenden R, Peebles TC (1974). Effects of fluoride supplementation from birth on deciduous and permanent teeth. Arch Oral Biol 19:321-326.

Adair SM, Wei SH (1978). Supplemental fluoride recommendations for infant based on dietary fluoride intake. Caries Res 12:76-82.

American Acadamy of Pediatrics, Council on Nutrition (1972). Fluoride as a nutrient. Pediatrics 49:456-459.

American Academy of Pediatrics, Council on Nutrition (1979). Fluoride supplementation: revised dosage schedule. Pediatrics 63:150-152.

American Academy of Pediatrics, Council on Nutrition (1986). Fluoride supplementation. Pediatrics 77:758-761.

American Dental Association, Council on Dental Therapeuties (1984). Accepted dental therapeutics. 40th edition. Chicago: American Dental Association, 342-354.

Angmar-Månsson B, Whitford GM(1990). Environmental and physiological factors affecting dental fluorosis. J Dent Res 69 (Spec Iss):706-713.

Ast DB, Smith DJ, Wachs B, Cantwell KT (1956). The Newburgh-Kingston caries-fluorine study. XIV. Combined clinical and roentgenographic dental findings after ten years of fluoride experience. $J$ Am Dent Assoc 52:314-325.

Baelum V, Fejerskov O, Manji F, Larsen MJ (1987). Daily dose of fluoride and dental fluorosis. Tandlaegebladet 91:452-456.

Barnhart WE, Hiller LK, Leonard GJ, Michaels E (1974). Dentifrice usage and ingestion among four age groups. J Dent Res 53:1317-1322.

Baxter PM (1980). Toothpaste ingestion during toothbrushing by school children. Br Dent $J$ 148:125-128.

Behrman RE, Kliegman R (1990). Essentials of pediatrics. Philadelphia: Saunders, 4-30.

Beltran ED, Szpunar SM (1988). Fluoride in toothpastes for children: suggestions for change. Pediatric Dent 3:185-188.

Brunelle JA (1989). The prevalence of dental fluorosis in U.S. children (abstract). J Dent Res 68:995.

Bruun C, Thylstrup A (1988). Dentifrice usage among Danish children. $J$ Dent Res 67:1114-1117.

Burt BA, Eklund SA, Morgan KJ, Larkin FE, Guire KE, Brown LO, Weintraub JA (1988). The effects of sugars intake and frequency of ingestion on dental caries increment in a three-year longitudinal study. $J$ Dent Res 67:1422-1429.

Chandra S, Sharma R, Thergaonkar VP, Chaturvedi SK (1980). Determination of optimal fluoride concentration in drinking water in an area in India with dental fluorosis. Community Dent Oral Epidemiol 8:92-96.
Cholak J (1959). Fluorides: a critical review. I. The occurrence of fluoride in air, food, and water. J Occup Med 1:501-511.

Clovis J, Hargreaves JA (1988). Fluoride intake from beverage consumption. Community Dent Oral Epidemiol 16:11-15.

Dabeka RW, Karpinski KF, McKenzie AD, Bajdik CD (1986). Survey of lead, cadmium and fluoride in human milk and correlation of levels with environmental and food factors. Food Chem Toxicol 24:913-921.

Dabeka RW, McKenzie AD (1987). Lead, cadmium, and fluoride levels in market milk and infant formulas in Canada. JOffic Analyt Chem Assoc 70:754-757.

Dabeka RW, McKenzie AD, Conacher HB, Kirkpatrick DC (1982). Determination of fluoride in Canadian infant foods and calculation of fluoride intakes by infants. Can J Public Health 73:188-191.

Dabeka RW, McKenzie AD, Lacroix GM (1987). Dietary intakes of lead, cadmium, arsenic and fluoride by Canadian adults: a 24-hour duplicate diet study. Food Addit Contam 4:89-101.

Dean HT (1942). The investigation of physiological effects by the epidemiological method. In: Moulton FR, editor. Fluorine and dental health. Washington, DC: American Association for the Advancement of Science, 23-31.

Driscoll WS, Horowitz HS, Meyers RJ, Heifetz SB, Kingman A, Zimmerman ER (1986). Prevalence of dental caries and dental fluorosis in areas with negligible, optimal, and above-optimal fluoride concentrations in drinking water. J Am Dent Assoc 113:29-33.

Eklund SA, Burt BA, Ismail Al, Calderone JJ (1987). High-fluoride drinking water, fluorosis, and dental caries in adults. J Am Dent Assoc 114:324328 .

Ekstrand J (1989). Fluoride intake in early infancy. J Nutr 119:1856-1860.

Ekstrand J, Ehrnebo M (1980). Absorption of fluoride from fluoride dentifrices. Caries Res 14:96-102.

Ekstrand J, Hardell LI, Spak CJ (1984a). Fluoride balance studies on infants in a 1-ppm-water-fluoride area. Caries Res 18:87-92.

Ekstrand J, Koch G (1980). Systemic fluoride absorption following fluoride gel application. J Dent Res 59:1067.

Ekstrand J, Koch G, Petersson LG (1983). Plasma fluoride concentrations in pre-school children after ingestion of fluoride tablets and toothpaste. Caries Res 17:379-384.

Ekstrand J, Spak CJ, Ehrnebo M (1982). Renal clearance of fluoride in a steady state condition in man: influence of urinary flow and $\mathrm{pH}$ changes by diet. Acta Pharmacol Toxicol 50:321-325.

Ekstrand J, Spak CJ, Falch J, Afseth J, Ulvestad H (1984b). Distribution of fluoride to human breast milk following intake of high doses of fluoride. Caries Res 18:93-95.

Ellingsen JE, Ekstrand J (1985). Plasma fluoride levels in man following intake of $\mathrm{SnF}_{2}$ in solution or toothpaste. J Dent Res 64:1250-1252.

Environmental Protection Agency (1986). National primary and secondary drinking water regulations: fluoride, final rule. Fed Register 51:1139611412.

Ericsson Y, Forsman B (1969). Fluoride retained from mouthrinsing and dentifrices in preschool children. Caries Res 3:290-299.

Ericsson Y, Ribelius U (1971). Wide variations of fluoride supply to infants and their effect. Caries Res 5:78-88.

Evans RW (1989). Changes in dental fluorosis following an adjustment to the fluoride concentration of Hong Kong's water supplies. Adv Dent Res 3:154-160.

Farkas CS, Farkas EJ (1974). Potential effect of food processing on the fluoride content of infant foods. Science Total Environment 2:399-405.

Featherstone JDB, Shields CP (1988). A study of fluoride in New York state residents. Final report to New York State Department of Health. 29 pp.

Fejerskov O, Manji F, Baelum V (1990). The nature and mechanisms of dental fluorosis in man. J Dent Res 69 (Spec Iss):692-700.

Fejerskov O, Stephen KW, Richards A, Speirs R (1987). Combined effect of systemic and topical fluoride treatments on human deciduous teethcase studies. Caries Res 21:452-459.

Filippo FA, Battistone GC (1971). The fluoride content of a representative diet of the young adult male. Clin Chim Acta 31:453-457.

Forrester DJ, Schulz EM Jr, editors (1974). International workshop on 
fluorides and dental caries reductions. Baltimore, MD: University of Maryland.

Forsman B (1977). Early supply of fluoride and enamel fluorosis. Scand $J$ Dent Res 85:22-30.

Glass RL, Peterson JK, Zuckerberg DA, Naylor MN (1975). Fluoride ingestion resulting from the use of a monofluorophosphate dentifrice by children. Br Dent $J$ 138:423-426.

Haikel Y, Voegel JC, Frank RM (1986). Fluoride content of water, dust, soils and cereals in the endemic dental fluorosis area of Khouribga (Morocco). Arch Oral Biol 31:279-286.

Haimonot RT, Fekadu A, Bushra B (1987). Endemic fluorosis in the Ethiopian rift valley. Trop Geog Med 39:209-217.

Hargreaves JA, Ingram GS, Wagg BJ (1970). Excretion studies of the ingestion of a monofluorophosphate toothpaste by children. Caries Res 4:256-268.

Hargreaves JA, Ingram GS, Wagg BJ (1972). A gravimetric study of the ingestion of toothpaste by children. Caries Res 6:236-243.

Heifetz SB, Driscoll WS, Horowitz HS, Kingman A (1988). Prevalence of dental caries and dental fluorosis in areas with optimal and aboveoptimal water-fluoride concentrations: a 5-year follow-up survey. $J \mathrm{Am}$ Dent Assoc 116:490-495

Holm AK, Andersson R (1982). Enamel mineralization disturbances in 12 year-old children with known early exposure to fluorides. Community Dent Oral Epidemiol 10:335-339.

Houwink B, Wagg BJ (1979). Effect of fluoride dentifrice usage during infancy upon enamel mottling of the permanent teeth. Caries Res 13:231-237.

Ismail AI, Brodeur J-M, Kavanagh M, Boisclair G, Tessier C, Picotte L (1990). Prevalence of dental caries and dental fluorosis in students, 1117 years of age, in fluoridated and non-fluoridated cities in Quebec. Caries Res 24:290-297.

Ismail AI, Burt BA, Hendershot GE, Jack S, Corbin SB (1987). Findings from the dental care supplement of the national health interview survey, 1983. J Am Dent Assoc 114:617-621.

Johnson J Jr, Bawden JW (1987). The fluoride content of infant formulas available in 1985. Pediatric Dent 9:33-37.

Jolly SS, Singh BM, Mathur OC, Malhotra KC (1968). Epidemiological, clinical, and biochemical study of endemic dental and skeletal fluorosis in Punjab. Br Med J 4:427-429.

Kramer L, Osis D, Wiatrowski E, Spencer H (1974). Dietary fluoride in different areas in the United States. Am I Clin Nutr 27:590-594.

Kumar JV, Green EL, Wallace W, Carnahan T (1989). Trends in dental fluorosis and dental caries prevalences in Newburgh and Kingston, NY. Am J Public Health 79:565-569.

Larsen MJ, Kirkegaard E, Fejerskov O, Poulsen S (1985a). Prevalence of dental fluorosis after fluoride-gel treatments in a low-fluoride area. $f$ Dent Res 64:1076-1079.

Larsen MJ, Kirkegaard E, Poulsen S (1987). Patterns of dental fluorosis in a European country in relation to the fluoride concentration of drinking water. I Dent Res 66:10-12.

Larsen MJ, Kirkegaard E, Poulsen S, Fejerskov O (1989). Dental fluorosis among participants in a non-supervised fluoride tablet program. Community Dent Oral Epidemiol 17:204-206.

Larsen MJ, Richards A, Fejerskov O (1985b). Development of dental fluorosis according to age at start of fluoride administration. Caries Res 19:519-527.

Leverett DH (1982). Fluorides and the changing prevalence of dental caries. Science 217:26-30.

Leverett DH (1986). Prevalence of dental fluorosis in fluoridated and nonfluoridated communities-a preliminary investigation. J Public Health Dent 46:184-187.

Leverett DH (1991). Appropriate uses of systemic fluoride: considerations for the '90s. J Public Health Dent 51:42-47.

Margolis FJ, Burt BA, Schork MA, Bashshur RL, Burns TL (1980). Fluoride supplements for children; a survey of physicians' prescription practices. Am J Dis Child 134:865-868.

Marier JR, Rose D (1972). Environmental fluoride. NRC Publ. No. 12,226.
Ottawa: NRC-Canada, 23.

McClure FJ (1943). Ingestion of fluoride and dental caries. Quantitative relations based on food and water requirements of children 1 to 12 years old. Am J Dis Child 66:362-369.

McClure FJ (1949). Fluorine in foods; survey of recent data. Public Health Rep 64:1061-1074.

McClure FJ, Zipkin I (1958). Physiological effects of fluoride as related to water fluoridation. Dent Clin N Am:411-458.

McKnight-Hanes MC, Leverett DH, Adair SM, Shields CP (1988). Fluoride content of infant formulas: soy-based formulas as a potential factor in dental fluorosis. Pediatric Dent 10:189-194.

Milsom K, Mitropoulos CM (1990). Enamel defects in 8-year-old children in fluoridated and non-fluoridated parts of Cheshire. Caries Res 24:286289.

Myers HM (1978). Fluorides and dental fluorosis. Monogr Oral Science 7:174.

Myers HM (1983). Dose-response relationship between water fluoride levels and the category of questionable dental fluorosis. Community Dent Oral Epidemiol 11:109-112.

Naccache H, Simard PL, Trahan L, Demers M, Lapointe C, Brodeur J.M (1990). Variability in the ingestion of toothpaste by preschool children. Caries Res 24:359-363.

National Research Council, Food and Nutrition Board (1974). Recommended dietary allowances. 8th edition. Washington, DC: National Academy of Sciences, 98-99.

National Research Council, Food and Nutrition Board (1989). Recommended dietary allowances. 10th edition. Washington, DC: National Academy Press, 235-240.

Naylor MN, Melville M, Wilson RF, Ingram GS, Wagg BJ (1971). Ingestion of dentifrice by young children; a pilot study using a fecal marker (abstract). J Dent Res 50:887.

Ophaug RH, Singer L, Harland BF (1980a). Estimated fluoride intake of 6month-old infants in four dietary regions of the United States. A $\mathrm{m} \mathrm{Clin}$ Nutr 33:324-327.

Ophaug RH, Singer L, Harland BF (1980b). Estimated fluoride intake of average two-year-old children in four dietary regions of the United States. J Dent Res 59:777-781.

Ophaug RH, Singer L, Harland BF (1985). Dietary fluoride intake of 6month and 2-year-old children in four dietary regions of the United States. Am J Clin Nutr 42:701-707.

Osis D, Kramer L, Wiatrowski E, Spencer H (1974). Dietary fluoride intake in man. J Nutr 104:1313-1318.

Osuji OO, Leake JL, Chipman ML, Nikiforuk G, Locker D, Levine N (1988). Risk factors for dental fluorosis in a fluoridated community. J Dent Res 67:1488-1492.

Pendrys DG, Katz RV (1989). Risk of enamel fluorosis associated with fluoride supplementation, infant formula, and fluoride dentifrice use. Am J Epidemiol 130:1199-1208.

Pendrys DG, Stamm JW (1990). Relationship of total fluoride intake to beneficial effects and enamel fluorosis. J Dent Res 69(Spec Iss):529-538.

Rao GS (1984). Dietary intake and bioavailability of fluoride. Ann Rev Nutr 4:115-136.

Rautner K, Einwag J (1988). Human plasma fluoride levels following intake of dentifrices containing aminefluoride or monofluorophosphate. Arch Oral Biol 33:543-546.

Richards A, Kragstrup J, Josephsen K, Fejerskov O (1986). Dental fluorosis developed in post-secretory enamel. J Dent Res 65:1406-1409.

Ripa LW (1991). A critique of topical fluoride methods (dentifrices, mouthrinses, operator-, and self-applied gels) in an era of decreased caries and increased fluorosis prevalence. $J$ Public Health Dent 51:2341.

Russell AL (1962). Dental fluorosis in Grand Rapids during the seventeenth year of fluoridation. $J$ Am Dent Assoc 65:608-612.

Simard PL, Lachapelle D, Trahan L, Naccache H, Demers M, Brodeur J-M (1989). The ingestion of fluoride dentifrice by young children. $J$ Dent Child 56:177-181.

Singer L, Ophaug R (1979). Total fluoride intake of infants. Pediatrics 
63:460-466.

Singer L, Ophaug RH, Harland BF (1980). Fluoride intakes of young male adults in the United States. Am J Clin Nutr 33:328-332.

Singer L, Ophaug RH, Harland BF (1985). Dietary fluoride intake of 15-19year-old male adults residing in the United States. J Dent Res 64:13021305.

Spak CJ, Ekstrand J, Zylberstein D (1982). Bioavailability of fluoride added by baby formula and milk. Caries Res 16:249-256.

Spencer H, Osis D, Lender M (1981). Studies of fluoride metabolism in man. A review and report of original data. Science Total Envir 17:1-12.

Szpunar SM, Burt BA (1987). Trends in the prevalence of dental fluorosis in the United States: a review. I Public Health Dent 47:71-79.

Szpunar SM, Burt BA (1988). Dental caries, fluorosis, and fluoride exposure in Michigan schoolchildren. J Dent Res 67:802-806.

Szpunar SM, Burt BA (1990). Fluoride exposure in Michigan schoolchildren. J Public Health Dent 50:18-23.

Taves DR (1979). Is fluoride intake in the United States changing? In: Johansen E, Taves DR, Olsen TO, editors. Continuing evaluation of the use of fluorides. Boulder, CO: Westview, 149-157.

Taves DR (1983). Dietary intake of fluoride ashed (total fluoride) v. unashed (inorganic fluoride) analysis of individual foods. Br J Nutr 49:295-301.

Tinanoff N, Mueller B (1978). Fluoride content in milk and formula for infants. J Dent Child 45:53-55.

Triol CW, Mandanas BY, Juliana GF, Yraolo B, Cano-Arevalo M, Volpe AR (1987). A clinical study of children comparing anticaries effect of two fluoride dentifrices; a 31-month study. Clin Prev Dent 9:22-24.

U.S. Public Health Service (1991). Review of fluoride benefits and risks, report of the ad hoc subcommittee on fluoride. Washington, DC: U.S. Government Printing Office, 45-47.

Whitford GM (1986). Fluoride metabolism. In; Newbrun E, editor. Fluorides and dental caries. 3rd edition. Springfield, IL: Thomas, 174198

Whitford GM, Allmann DW, Shahed AR (1987). Topical fluorides: effects on physiologic and biochemical processes. J Dent Res 66:1072-1078.

Wiatrowski E, Kramer L, Osis D, Spencer H (1975). Dietary fluoride intake of infants. Pediatrics 55:517-522.

Williams JE, Zwemer JD (1990). Community water fluoride levels, preschool dietary patterns, and the occurrence of fluoride enamel opacities. J Public Health Dent 50:276-281.

Winter GB, Holt RD, Williams BF (1989). Clinical trial of a low-fluoride toothpaste for young children. Int Dent $J$ 39:227-235.

Woltgens JH, Etty EJ, Nieuwland WM, Lyaruu DM (1989). Use of fluoride by young children and prevalence of mottled enamel. Adv Dent Res 3:177-182. 